\title{
EDITORIAL
}

\section{Editorial PIAM October 2018}

\author{
Cynthia Wirth ${ }^{1} \cdot$ Martin Schäfer $^{2}$
}

Published online: 12 November 2018

(c) Springer Nature Switzerland AG 2018

"Progress in Additive Manufacturing" started in 2016 with the approach of covering new findings from the industrial and scientific world to bring together technology expertise and consolidate knowledge. It also underlines the scope of addressing the interdisciplinary nature of AM in one single journal. The last 2 years have shown that this concept is more than necessary as the investigations within the different areas such as material, data preparation, processes and postprocessing have grown. The publications in PIAM focusing on industrial production and industrial applications have also increased. Therefore, a clear picture of the developments is absolutely essential to establish sustainable knowledge.

The industry has published a lot of success stories regarding the use of AM under "real industrial conditions". Key players from the energy sector, such as Siemens and GE, showed the operation of turbine burners without failure or the manufacturing of thousands of nozzles. New machines have been launched in the market with larger building envelopes or having more powerful energy sources. There are laser melting machines operating simultaneously with four laser beams, extrusion machines with more efficient print heads, and finally automated systems and monitoring units being implemented to improve quality assurance and to serve the next revolution of "big data". Furthermore, a lot of new but old conventional processes appear in the AM world such as material extrusion process using metal filled filaments or directed energy deposition with wire. The discussions about adapted materials, material combinations and $\mathrm{AM}$ integration in production chains and $\mathrm{AM}$ hybrid manufacturing are all in full swing.

Besides all these excellent and brilliant innovations, the fundamental building blocks of the AM processes, material and part properties are still not completely understood and there is still a demand for material, data and quality, further pressing the need for standards for the industry. The previous issues of "Progress in Additive Manufacturing" help our readers to comprehend a variety of topics to meet these concerns and to stay abreast of technological changes. Design aspects and material issues such as properties of AM parts; functional integration, part build orientation, quality issues and testing methods have been addressed, as well as topics about high-performance materials such as ceramics and composites are explored. At the same time, experimental work about limitations and failures have been investigated. Industrial topics include those that provide industry use cases about the implementation of combined and hybrid processes. Our papers also include trends such as process monitoring, modelling, database development, the production of electronic components and cybersecurity.

It is our wish that the PIAM journal will continue to contribute knowledge to the industrial and scientific communities. Without the dedicated work of our Editorial Board and reviewers, none of this would have been possible. Of course, to all authors and contributors, we extend our sincere thank you for the support and trust.

Martin and Cynthia

Editors-in-Chief

Progress in Additive Manufacturing Journal

October 2018

Publisher's Note Springer Nature remains neutral with regard to jurisdictional claims in published maps and institutional affiliations.

Martin Schäfer

martin.schaefer@siemens.com

1 Power and Gas Division, Large Gas Turbine, Siemens AG, Huttenstr. 12, 10553 Berlin, Germany

2 Corporate Technology, Research and Technology Center, Siemens AG, Siemensdamm 50, 13629 Berlin, Germany 